\title{
Splenosis pleurae
}

\author{
A G JARIWALLA AND N K AL-NASIRI ${ }^{1}$ \\ From the Department of Medicine, Royal Gwent/St Woolos Hospitals, Newport, Gwent, UK
}

Splenosis is the autotransplantation of splenic tissue, usually after traumatic rupture of spleen. Reports of splenosis pleurae are rare. Of the six cases reported so far, there is only one (Shaw and Shafi, 1937) in the British literature. On the other hand, splenosis peritonei has been well documented. The transplants have always followed traumatic splenic rupture, diaphragmatic rupture, and splenectomy. It is important to recognise this condition to avoid unnecessary surgical procedures.

\section{Case report}

A 17-year-old labourer presented with a few weeks' history of a painful lump in the right groin, lethargy, and weakness. A road traffic accident in 1964 had resulted in fractures of the left inferior pubic ramus and left seventh rib and ruptured spleen and diaphragm. Splenectomy and repair of the diaphragm were undertaken. He remained well until his present illness. He was afebrile, and the only abnormality was painless, generalised lymphadenopathy.

\section{INVESTIGATIONS}

Results of investigations showed haemoglobin $14 \cdot 3 \mathrm{~g} / \mathrm{dl}$, and white cell count $7 \cdot 3 \times 10^{3}$ (normal differential count). The following tests were normal: Paul Bunnel, ESR (Westergren); viral agglutinations; serum calcium; liver function, immunoglobulins and protein electrophoresis; urea and electrolytes; electrocardiography; intravenous pyelogram; and hydatid complement fixation. Chest radiograph (fig 1) showed rounded lesions in the left mid-zone. A chest radiograph in 1964 had been normal.

At exploratory thoracotomy, multiple purple, sessile nodules, some lobulated, were removed from the left parietal, visceral, and mediastinal pleura. They ranged from one to three centimetres in diameter and had the appearance of small spleens. They were soft and surrounded by thin fibrous capsules, but no definite intrasplenic

'Present address: Department of Surgical Pathology, St Thomas's Hospital, London SE1. trabeculae could be seen. Microscopic examination (fig 2) showed that red pulp predominated over the white. The white pulp consisted of clusters of lymphocytes with no germinal centres. In most of these clusters were arterioles either lying beside the lymphoid follicles or occasionally centrally, indistinguishable from malpighian corpuscles. The red pulp consisted of endothelial-lined sinusoids, histiocytes, and scattered lymphocytes. The connective tissue capsule, in some areas, was well vascularised and contained rather large arteries and veins. The fibrous trabeculae normally present in the spleen were not shown in any of the nodules. The adjacent lung showed patchy areas of fibrosis and old haemorrhage compatible with previous trauma.

\section{CLINICAL PROGRESS}

The patient made a good postoperative recovery. The lymphadenopathy completely regressed, the cause remaining undiscovered.

\section{Discussion}

Splenosis rarely follows traumatic splenic rupture and is an important differential diagnosis of multiple pulmonary opacities when there is a history of trauma to the spleen. Other causes of similar radiological changes are accessory spleens, endometriosis, intrathoracic and metastatic neoplasms, and haemangiomas. Splenotic nodules presumably result from autotransplantation on the pleura after scattering of splenic red pulp fragments from the ruptured spleen. Blood-borne spread is unlikely because the splenic tissue is not seen in other organs.

Splenotic nodules were noted (Schilling, 1907) at a laparotomy, but the phenomenon of autotransplantation and splenosis was first suggested by Buchbinder and Lipkoff (1939). Finger clubbing, dyspnoea, and cervicofacial venous congestion have been described in association with thoracic transposition of the spleen. These splenotic nodules may be responsible for a relapse of a haematological disorder after removal of the spleen for the condition (Fleming et al, 1976. The absence 


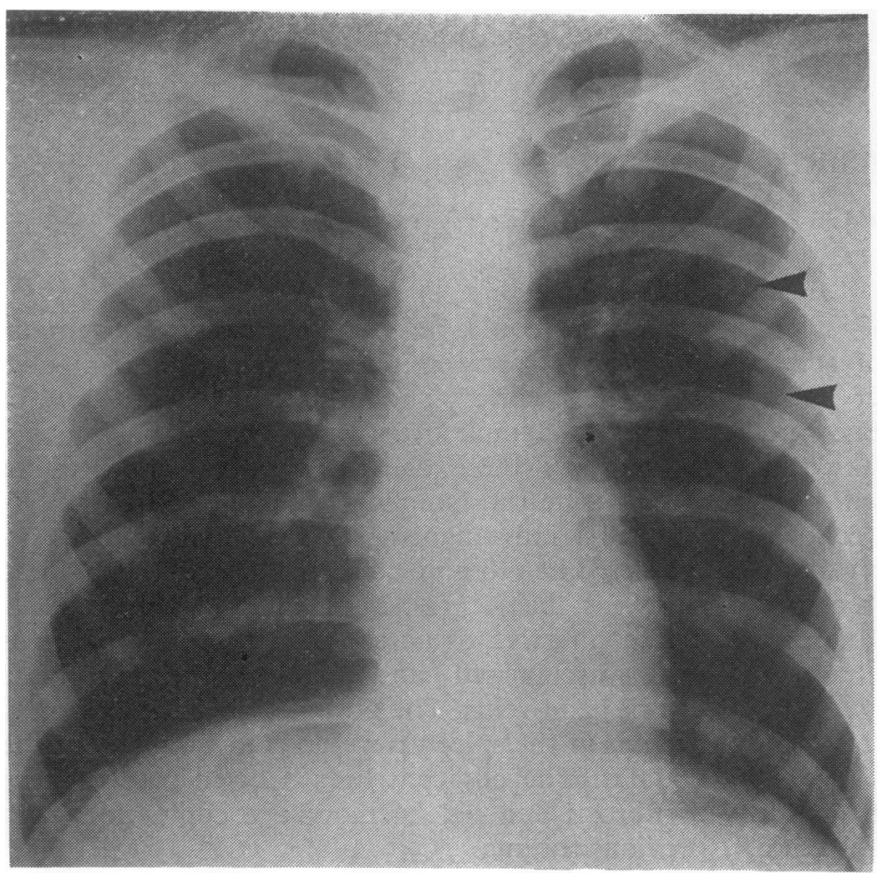

Fig 1 Splenic deposits in left lateral hemithorax (arrows).

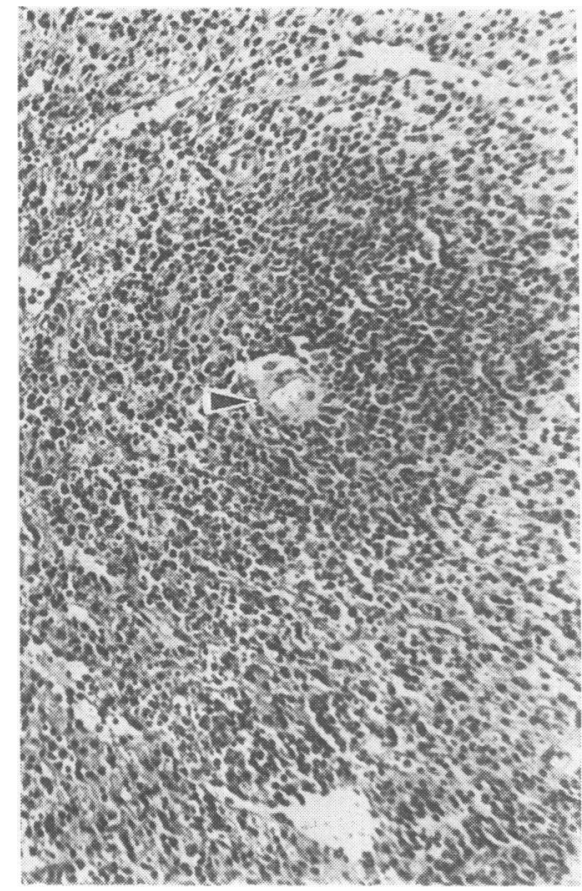

Fig 2 One lymphoid follicle with central arteriole (arrow) removed from left pleural cavity. of Howell-Jolly bodies, siderocytes, and other features found in the peripheral blood film after splenectomy may suggest the presence of residual splenic tissue. Various radioisotope scanning techniques (Jacobson and De Nardo, 1971) have been used to diagnose functioning splenic tissue.

Although splenosis pleurae is a very rare condition, this being only the second case report in British literature, it should be considered in the differential diagnosis of intrapulmonary opacities in the presence of history of splenic rupture.

We would like to express our thanks to Dr E G Anderson, Dr H J Lloyd, and Mr T H L Rosser for permission to publish the case and Dr Roger Seal for his help.

\section{References}

Buchbinder, J H, and Lipkoff, C J (1939). Splenosis: multiple peritoneal splenic implants following abdominal injury. Surgery, 6, 927-934.

Fleming, C R, Dickson, E R, and Harrison, E G (1976). Splenosis: auto-transplantation of splenic tissue. American Journal of Medicine, 61, 414-419.

Jacobson, S J, and De Nardo, G L (1971). Splenosis demonstrated by splenic scan. Journal of Nuclear Medicine, 12, 570-573.

Schilling, K (1907). Uber Einen Fall von Multiplen Nebenmilzen. Virchows Archiv für Pathologische Anatomie und Physiologie und für Klinische Medizin, 188, 65-87.

Shaw, A F, and Shafi, A (1937). Traumatic autoplastic transplantation of splenic tissue in man with observation on the late results of splenectomy in six cases. Journal of Pathology and Bacteriology, 45, 215-235.

Requests for reprints to: Dr A G Jariwalla, Department of Medicine, Llandough Hospita!, Penarth, Cardiff. 